\title{
A Self-sustaining, Autonomous, Wireless-Sensor Beacon Powered from Long-Range, Ambient, RF Energy
}

\author{
Rushi Vyas*, Benjamin Cook, Dr. Yoshihiro Kawahara, Dr. Manos Tentzeris \\ School of Electrical and Computer Engineering, Georgia Institute of Technology \\ *Rushi.Vyas@gatech.edu
}

\begin{abstract}
A novel embedded sensing and wireless relay mote that powers itself from long range digital TV signals is presented. With an improved antenna, RF-DC circuit, and an energy-aware embedded-firmware design, enough wireless power from a distributed TV tower network can be harnessed for wireless sensor telemetry. A microcontroller and $900 \mathrm{MHz}$ transmitter for the telemetry has been powered on and sustained from ambient TV signals at previously unreported range of 6.5 km from a TV broadcast source.

Index Terms - wireless power transfer, energy harvesting, antenna, rectifier, PIC, microcontroller, transmitter, sensors.
\end{abstract}

\section{INTRODUCTION}

Energy harvesting is an attractive alternative to batteries for powering autonomous sensors required for pervasive applications such as large area structural health monitoring, environmental and agricultural sensing, smart meters etc. While material costs of sensors have been on a downward trend, the logistics of periodic battery replacement in them can be expensive especially in networks over larger areas or scale. While increasing power efficiency and power density of batteries have extended the operating lifetime of sensors, battery replacement in non-accessible or rugged environments can still prove to be cumbersome and expensive. Ambient wireless power present in urban areas due to cellular, $\mathrm{WiFi}$ and modern digital TV broadcasts in most urban areas can be used as a potential power source for autonomous sensors in areas or periods where solar has insufficient light intensity and battery replacements prove costly. While wireless signals do attenuate rapidly from their source, by exploiting the multicarrier make up of modern wireless communication signals, microcontroller and transceiver relays can be successfully powered and sustained at distances of over $6.5 \mathrm{~km}$ from broadcast sources as presented in this work.

\section{WIRELESS ENERGY HARVESTING BEACON SYSTEM (WEH)}

An energy harvesting prototype capable of capturing power from ambient wireless power present in ISDB-T digital TV signals at long range has been presented by Vyas et. al in [1]. The system in [1] comprised of a dipole antenna and a rectifier circuit producing a $2.9 \mathrm{~V}$ across an output capacitor from several TV broadcast sources atop the Tokyo TV tower 6.5 $\mathrm{km}$ away by exploiting the multicarrier make up of each of the 64-QAM modulated digital TV channels under the ISDB-T standards [2]. The wireless TV spectrum in Tokyo shown in [1] contained multiple TV channels each $6 \mathrm{MHz}$ wide adjacent to each other, in the 500-600 $\mathrm{MHz}$ band, and all emanating from the same source. By comparison wireless TV broadcast infrastructure in the North America uses a different standard called ATSC to broadcast out high definition content. Also, the TV broadcast towers tend to be scattered with different TV channels sent out from different towers located at varying locations to maximize coverage [3]. The Federal Communication Commission (FCC) provided site survey of downtown Atlanta shows the distribution of TV towers for some of the popular US based TV channels in Fig. 1. The measured wireless power spectrum measured at the site of this work due to the TV towers in Fig.1 is shown in Fig.2, and shows heavy spectral activity in a similar frequency band between 500-700 MHz, which is divided up among different TV channels by the FCC in the US.

Compared to ISDB-T digital TV signals in Tokyo covered in [1], the scattered assignment and location of ATSC standard digital TV broadcast infrastructure in the US show gaps in between the channels where none or insufficient wireless power exists as shown in Fig. 1 and Fig.2. Also, the measured ambient E-field at the site of measurements in Atlanta has lower magnitudes of between 0.01 and $0.035 \mathrm{~V} / \mathrm{m}$ compared to those observed in downtown Tokyo that were upto $0.8 \mathrm{~V} / \mathrm{m}$ in spite of being at the same distance from the broadcast towers [1].

In order to compensate for these deficiencies an improved ambient wireless energy harvesting prototype (WEH) is designed to harness more power from lower magnitude ATSC digital TV signals in the US. In addition to just a rectifier shown in [1], the WEH prototype in this work powers on and sustains an embedded microcontroller and a wireless transmitter for autonomous sensing and its wireless relay. The wireless energy harvesting system is shown in Fig. 3 and comprises of an optimized antenna to convert ambient E-field into an RF signal; an improved RF-DC converter circuit to step up and rectify the low RF signal across the antenna; an array of low leakage capacitors to collect rectified wireless power; a 16 bit embedded PIC24F microcontroller to provide an energy aware power management scheme and also a sensing platform through its many $\mathrm{ADC}$ and serial communication interfaces; and a $900 \mathrm{MHz}$ RFPIC transmitter to relay out any sensed information to a back-end network and onto the cloud. 


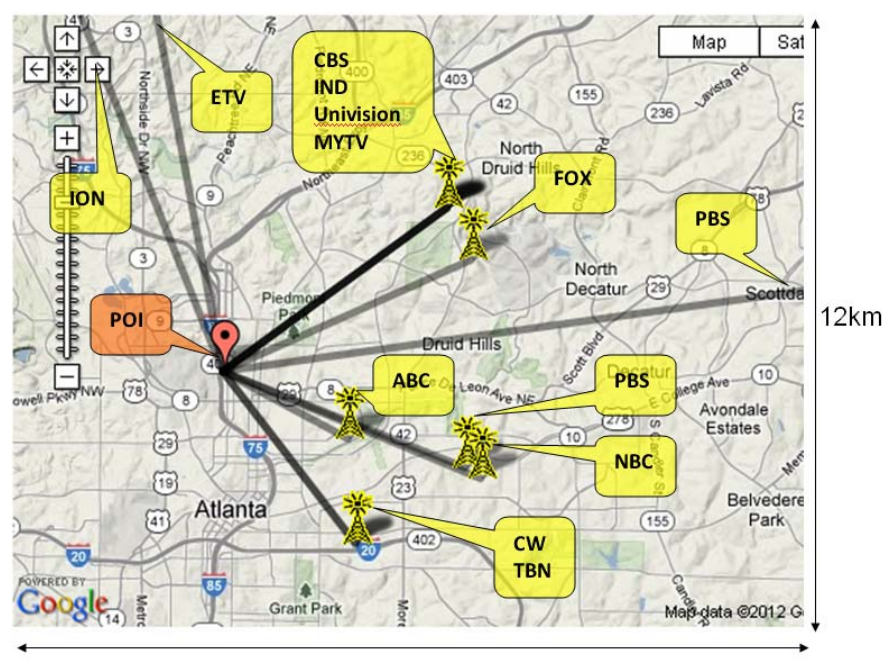

$15.4 \mathrm{~km}$

Fig. 1. Location of TV broadcast towers in Atlanta, USA with respect to the site of measurement.

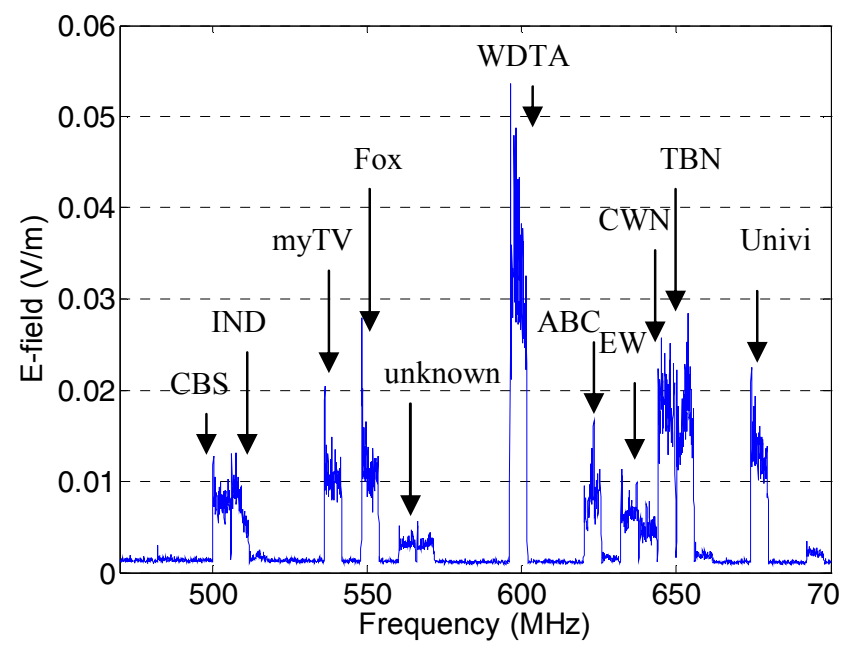

Fig. 2. Ambient wireless spectrum measured in midtown Atlanta

\section{WEH ANTENNA AND IMPROVED RF-DC CIRCUIT}

A miniaturized log periodic antenna design sized 31.5 by 21.5 square $\mathrm{cm}$, and optimized to have an antenna effective aperture area large enough in the $500-600 \mathrm{MHz}$ band was used to transduce enough of the incident Electric field to an RF signal. Log periodic antennas have typical gains of between 3 and $9 \mathrm{dBi}$ in the 500-700 $\mathrm{MHz}$ band, which help capture more power from fewer TV channels. The antenna's return loss is less than $10 \mathrm{~dB}$ in $500-600 \mathrm{MHz}$ band on account of its compactness. The amount of power transduced by the antenna from the ambient wireless TV signals when aligned in the North east direction towards the CBS, IND, Univision, MyTV and Fox TV towers $6.5 \mathrm{~km}$ away was measured with a Tektronix RSA30408A real time spectrum analyzer and is shown in table 1 . The antenna seems to capture the most amount of channel power from myTV TV channel occupying the 536-542 $\mathrm{MHz}$ band $(-16.29 \mathrm{dBm})$ followed by CBS ($16.92 \mathrm{dBm})$, IND $(-16.92 \mathrm{dBm})$ and Fox $(-22.15 \mathrm{dBm})$ in the 500-518 MHz and 548-554 MHz TV bands respectively. Even with a higher directivity, the total channel power captured by the antenna in a $100 \mathrm{MHz}$ bandwidth is half as much at $11.54 \mathrm{dBm}$ compared to $-8.44 \mathrm{dBm}$ in downtown Tokyo at roughly the same distance from the TV broadcast source. Similarly, the peak channel power measured is $1.92 \mathrm{~dB}$ lower than the one in Tokyo.

To compensate for the lower ambient power level, an optimized RF-DC converter circuit with roughly twice the efficiency as in [1] was designed and tested in the field. The turn on power required to power up the output $100 \mathrm{uF}$ charge tank of the RF-DC converter circuit with respect to the ambient measured TV channel powers in midtown Atlanta is shown in Fig. 4. Based on lab measurements, the optimized RF-DC converter circuit conjugately matched to the log periodic antenna at broadcast frequencies of TV channels CBS, IND, MyTV and Fox gave out close to 3.0V in lab. On site measurements of the energy harvesting prototype yielded an output between 3.1 and $3.4 \mathrm{~V}$ across it $100 \mathrm{uF}$ output charge tank capacitor in 4 minutes with antenna's end fire direction pointed in North east direction towards the CBS, IND, MyTV and FOX TV Towers.

\section{WEH EMBEDDED AND TRANSMITTER DESIGN}

Power management to sustain embedded sensing and beacon transmit operation for limited duty cycles, from just the $0.38 \mathrm{~mJ}$ of energy collected from ambient RF power every 4 minutes into a $100 \mathrm{uF}$ capacitor, was performed using a PIC24F 16-bit microcontroller programmed with an energy aware software design. Using the test setup in Fig.5, the WEH system was tested with multicarrier TV signals emulated using a Rohde and Schwarz SMJ100 vector signal generator similar to the one measured on site. Embedded peripherals on the PIC24F namely an Analog to digital converter and UART operating at $300 \mathrm{bps}$ that are useful for many analog and digital sensors could be powered up and sustained at just a $32 \mathrm{~Hz}$ clock every $10 \mathrm{sec}$ from $-13.92 \mathrm{dBm}$ of channel power present in CBS and IND TV channels as shown in Fig.6.

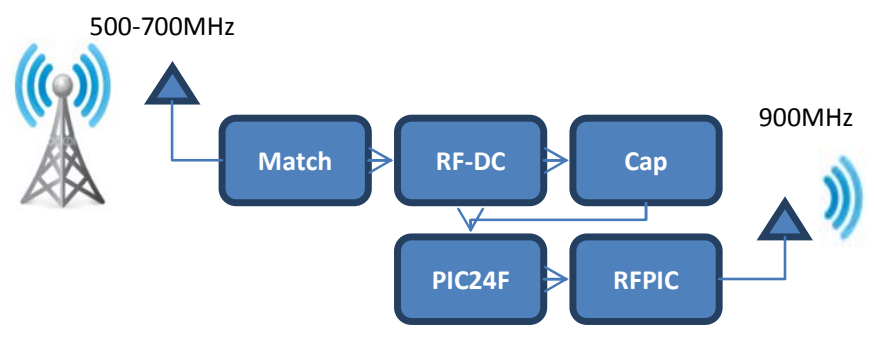

Fig. 3. Ambient Wireless Energy Harvesting system. 
Table 1. Ambient RF Power Captured by the Log Periodic Antenna Design at each of the ATSC Digital TV channels in Atlanta.

\begin{tabular}{|l|l|l|l|}
\hline TV Channels & Freq. Band & $\begin{array}{l}\text { Measured } \\
\text { Power }\end{array}$ \\
\hline & $(\mathrm{MHz})$ & $\mathrm{dBm}$ & $\mu$ watts \\
\hline CBS & $500-506$ & -16.92 & 20.32 \\
\hline IND & $506-512$ & -16.92 & 20.32 \\
\hline MyTV & $536-542$ & -16.29 & 23.5 \\
\hline Fox & $548-554$ & -22.15 & 6.24 \\
\hline WDTA & $596-608$ & -24.83 & 3.2 \\
\hline ABC,ETV,CW,TBN,Uni & $620-680$ & $<-24.83$ & $<3.2$ \\
\hline
\end{tabular}

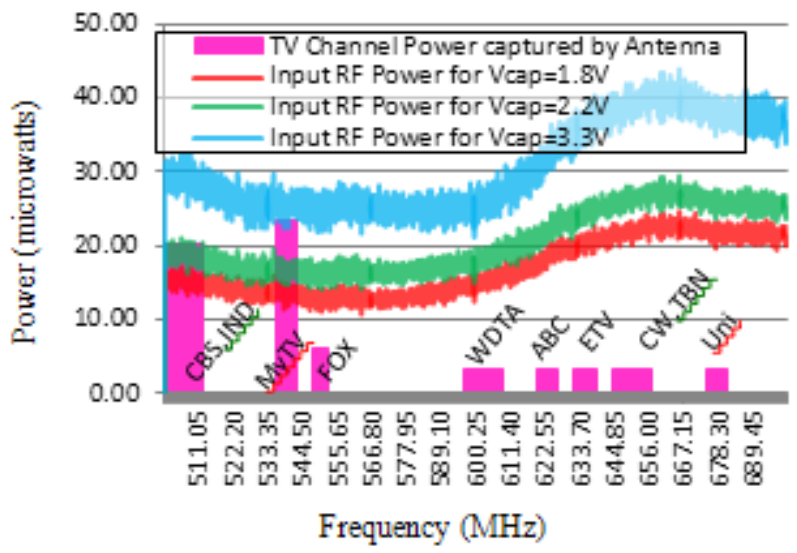

Fig. 4. RF-DC Converter circuit input turn on power required for output voltages of $1.8,2.2$ and $3.3 \mathrm{~V}$.

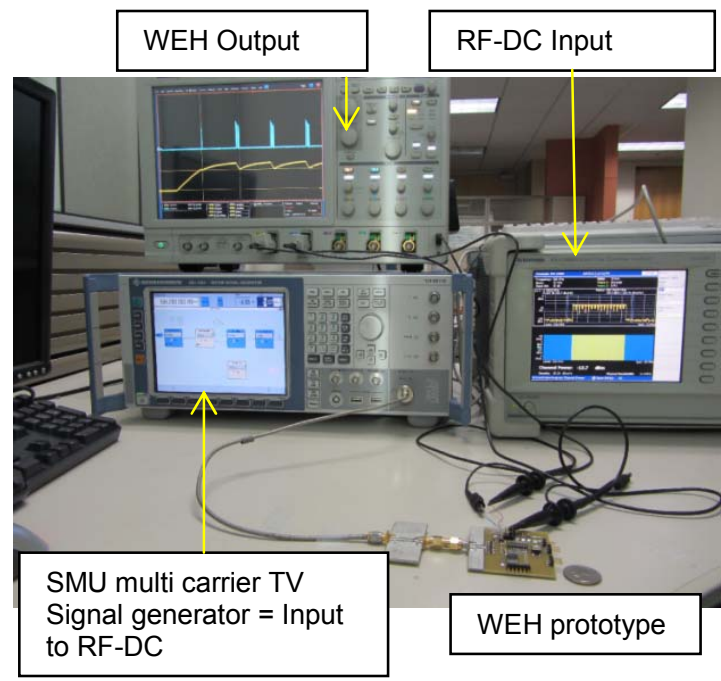

Fig. 5. Wireless energy harvesting prototype (WEH) test setup.

Also, from the $0.38 \mathrm{~mJ}$ of energy collected across a $100 \mathrm{uF}$ capacitor, an RFPIC transmitter transmitting $4.5 \mathrm{dBm}$ output power at frequency of $900 \mathrm{MHz}$, and consuming $12 \mathrm{~mA}$ of current can be powered on for $14 \mathrm{msec}$ as in Fig.7. This is useful for wirelessly relaying any sense information to a backend network.

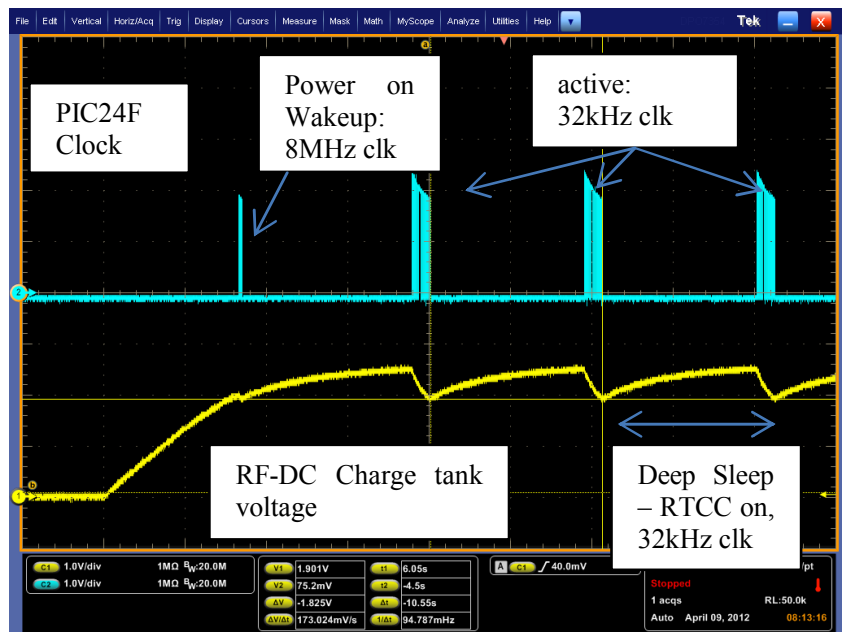

Fig. 6. RF-DC output charge tank and PIC24F operation with input RF channel power of $-13.92 \mathrm{dBm}$ (CBS and IND TV channels).

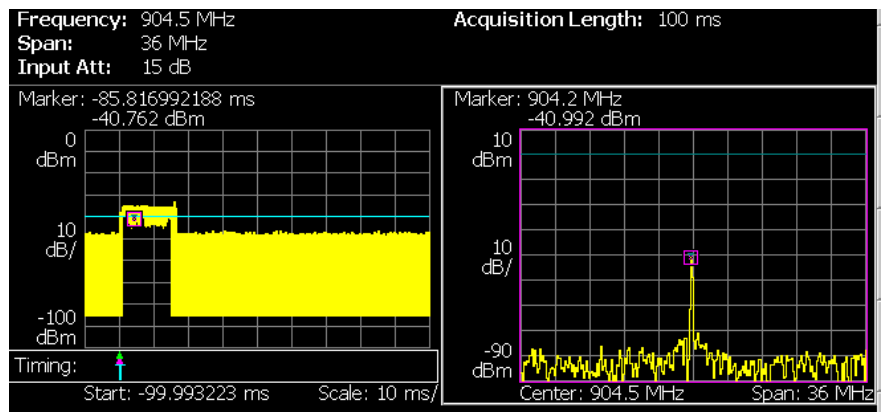

Fig. 7. RFPIC $900 \mathrm{MHz}$ transmitter transmitted beacon signal powered from $3.4 \mathrm{~V}$ charge up across $100 \mathrm{uF}$ charge tank capacitor as measured by Tektronix RSA30408A.

\section{CONCLUSION}

A novel embedded sensing and wireless relay platform that can power and sustain itself using long range digital TV signals at distance of $6.5 \mathrm{~km}$ is successfully implemented.

\section{ACKNOWLEDGEMENT}

The authors wish to acknowledge NEDO Japan, NSF and IFC alliance for their support.

\section{REFERENCES}

[1] R.Vyas et al., "A battery-less, energy harvesting device for long range scavenging of wireless power from terrestrial TV broadcasts," in IEEE MTT-S International, Montreal, Canada, June 2012, pp. 1-3.

[2] Agilent. (2005) DTV ISDB OFDM Project Example. [Online]. http://cp.literature.agilent.com/litweb/pdf/ads2005a/dtv/dtv124.h tml

[3] David Sparano. What Exactly is 8-VSB Anyway? [Online]. http://www.arrl.org/files/file/Technology/TV_Channels/8_Bit VSB.pdf 